\title{
Price Volatility for Selected Agricultural Commodities in Ethiopia: Evidence from GARCH Models
}

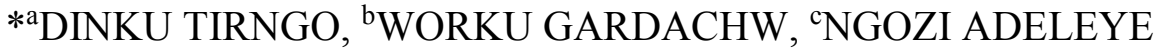 \\ ${ }^{a}$ Accounting and finance \\ Bahir Dar University, \\ Bahir Dar, ETHIOPIA \\ ORCID: 0000-0002-8609-3257 \\ ${ }^{\mathrm{b}}$ Accounting and finance \\ Injibara University, \\ Injibara, ETHIOPIA \\ ${ }^{\mathrm{c}}$ Economics \\ Covenant University, \\ Ota, NIGERIA \\ ORCID: 0000-0002-1274-714X
}

\begin{abstract}
This study models the volatility of returns for selected agricultural commodity prices in Ethiopia using the generalized autoregressive conditional heteroskedasticity $(\mathrm{GARCH})$ approach. GARCH family models, specifically threshold GARCH and exponential GARCH were employed to analyze the time varying volatility of selected agricultural commodities prices from 2010 to 2021. The data analysis results revealed that, out of the GARCH specifications, the EGARCH model with the normal distributional assumption of residuals was a better fit model for the price volatility of "teff" and "red pepper" in which their return series reacted differently to the "good" and "bad" news. The study indicated the existence of a leverage effect, which implied that the "bad" news could have a larger effect on volatility than the "good" news of the same magnitude, and the asymmetric term was statistically significant.
\end{abstract}

Key-Words: - Price volatility, Agricultural commodities, GARCH, TGARCH, EGARCH

Received: March 6, 2021. Revised: October 7, 2021. Accepted: October 25, 2021. Published: November 11, 2021.

\section{Introduction}

Volatility is a measure of changes in economic variables over time; in a strictly descriptive context, it is a measure of market difference from the previous period to the current period and also a measure of price variation from the previous period to the current period. It is crucial to note that variation in time is always problematic, for instance, when prices move along a smooth and well-established trend reflecting market fundamentals and well-known seasonal patterns [1]. However, price variations become problematic when it is difficult to predict and large in magnitude since it creating a level of uncertainty which increases risk for producers, traders, consumers and governments leading to sub-optimal decisions [1].

The evolution of price fluctuation originated from [2] paper which focused on the concept of the uncertainty of asset prices that is based on price movement and dynamics. According to [3], volatility clustering and leptokurtic patterns are the main characteristics of financial time series among others. Though, traditional econometric models assume a constant one-period forecast variance. [4] Pioneered modeling volatility where his work focused on changing variance using the autoregressive conditional heteroskedasticity (ARCH). These are mean zero, serially uncorrelated processes with nonconstant variances conditional on the past, but constant unconditional variances [5]. For such processes, the recent past gives information about the one-period forecast variance. The basis of an $\mathrm{ARCH}$ model is that there is time varying mean (heteroscedasticity) that depends (conditional) on lagged effect. Hence, large and small errors tend to cluster together when a big shock occurs in the previous period such that it is more likely that the variance of the current period will also be bigger and vice versa [5]. 
Various models were brought into volatility modeling [4] ARCH approach. For instance, [6] pioneered the generalized autoregressive conditional heteroskedasticity $(\mathrm{GARCH})$ model followed by the exponential GARCH (EGARCH) model [7], threshold GARCH (TGARGH) [8], and others became dominant in modeling conditional variance and risk prima.

In Engle's ARCH (q) model, the conditional variance is specified as a linear function of past sample variances large past square returns which imply a large conditional variance for the return. However, the ARCH model treats positive and negative returns in the same way and is very restrictive in parameters only whereas the GARCH (p, q) [6] model allows lagged conditional variances to enter into the model as well, in which conditional variance is expressed as a linear function of past squared innovations and of its past values, providing the non-negativity constraint. The GARCH model assumes only the magnitude but not the positivity or the negativity of unanticipated excess returns that determine feature variance. To overcome this weakness in the GARCH model, [7] proposed the EGARCH technique to allow for asymmetric effects. The EGARCH model consents positive and negative shocks of equal size to have different impacts on volatility which means negative shocks at time $t-1$ have a stronger impact on the variance at time $t$ than positive shocks [7] because the increase in risk was believed to come from the increased leverage induced by a negative shock.

The other model comparable to the exponential GARCH model, in allowing asymmetric shocks to volatility is the threshold GARCH model, in which volatility tends to increase with bad news and decrease with good news and it is introduced by [8]. Some of the differences in these two models are that the TGARCH makes volatility a function of nonnormalized innovations and provides additive modeling, while EGARCH does not. In modeling asymmetries, EGARCH imposes a constant structure at all lags whereas; different lags may yield contrary contributions in TGARCH cases.

Though most of these volatility models originated from the financial market perspectives increasing demand to make use of GARCH family models has come into exercise as a result of continuous fluctuation in agricultural commodity prices. The agricultural commodity market reacts more to positive news than negative news where speculative hoarding takes place [9]. According to [9] GARCH
$(1,1)$ for symmetric, and P GARCH $(1,1)$ for the asymmetric modeling were found to be the best models the Indian data, and for they explain volatility better in their category as the LM test values are least for them. signaling that these models are better in capturing the effect of volatility, than others, in the Indian agricultural market; agricultural commodity market quantities and prices are often random which introduces a large amount of risk and uncertainty into the process of market modeling and forecasting.

Also, the volatility in the prices of commodities has a direct impact on final consumers as the price of food is impacted by production costs as well as by inflation [10]. Moreover, the study conducted by [12] and which focused on modeling volatility of agricultural commodity by using monthly commodity food price index data in Nigeria showed ARMA $(2,1)-\mathrm{GARCH}$ $(1,1)$ and ARMA $(2,1)$-EGARCH $(1,1)$ models with student-t innovations were appropriate in describing the symmetric and asymmetric behaviors of the log returns.

In fact, many scholars have employed GARCH family models to model volatility of agricultural commodity price indexes using data from a variety of sources obtained from both developed and developing countries at different times. However they found a different model which fits best to model agricultural commodity prices index. Therefore the aim of this paper is to model the volatility of returns for selected agricultural commodity prices in Ethiopia using three generalized autoregressive conditional heteroscedasticity (GARCH) specifications namely, the standard GARCH, the Exponential GARCH (EGARCH), and the Threshold GARCH (TGARCH). For this purpose data were obtained from Central Statistics Agency (CSA).

The rest of the paper is structured as follows; section 2 reviews the extant literature; section 3 outlines the data and methodology; section 4 discusses the results; and section 5 concludes.

\section{Literature Review}

Commodity prices are characterized by a high degree of volatility (UNCTAD, 2019), and the worst is that the problem becomes serious in commodity dependent developing countries like Ethiopia.

As the agriculture sector is the mainstay of Ethiopia's economy, modeling volatility is highly demanding for investment decisions and policy recommendations and forecasting. Accordingly, [12], [10], and [11] are pioneers who model volatility specifically on agricultural commodity prices. [12] studied the autoregressive integrated moving average 
(ARIMA) model, GARCH model, and EGARCH model along with their estimation procedures for modeling and forecasting of three price series, specifically domestic and international edible oils price indices and the international cotton price 'Cotlook A' index. Their study revealed that the EGARCH model outperformed the ARIMA and the GARCH models in forecasting the international cotton price series primarily due to its ability to capture asymmetric volatility patterns.

[11] Also models volatility of agricultural commodities. The study concludes that ARMA $(2,1)$ GARCH $(1,1)$ and ARMA $(2,1)$-EGARCH $(1,1)$ models fits symmetric and asymmetric behaviors of the $\log$ returns which could describe best the log returns price volatility of selected agricultural commodity food products in Nigeria. The study further showed that the best fitted models were not necessarily the best forecast models.

Another study by [23] also supports asymmetric effect return of coffee price in Indonesia hence EGARCH is an appropriate model for this commodity.

Furthermore, by analyzing the GARCH family models, [10] suggested that volatility was present in the data, overall, GARCH was the best fitting model for the S\&P GSCI Agriculture Index during and after the financial crisis and EGARCH for the Brazilian Real and only the GJR-GARCH results for cocoa indicated the existence of leverage effects.

With special reference to the context of Ethiopia, researchers, for example, [1]), [13], [14], [5] have conducted studies that focused on modeling commodity price volatility. [1], in his study on selected agricultural products in Ethiopia, found that the ARCH and GARCH models were appropriate. In line with this, the results suggested that $\operatorname{GARCH}(1,1), \operatorname{GARCH}(1,2)$, and GARCH $(2,1)$ models were the most appropriate fitted models that a researcher could use to evaluate the volatility of the log-returns of the price of cereal, pulse and oil crops, respectively. Price volatility was persistent in all three categories (cereal, pulse and oil crops) of selected agricultural goods. [13] study revealed that the GARCH-M $(2,2)$ was found to be the best fit model for modeling and forecasting the gold price volatility in the Ethiopian market and [14] found that $\operatorname{ARIMA}(0,1,1)$ and $\operatorname{ARMA}(2,2)-\operatorname{GARCH}(2,1)$ with the normal distributional assumption for the residuals were adequate models for modeling and forecasting the volatility of the export price of Sesame in Ethiopia. Moreover, recently, [5] also conducted a study on modeling time-varying coffee price volatility in Ethiopia, and he found that the multiplicative GARCH-MIDAS model explained stylized facts that could not be captured by the standard GARCH model. As it is understood from the literature, there is no one best model which fits for all data series and the nature of the commodity. Thus, this study contributes to the literature by documenting the best fit volatility model for selected agricultural commodity prices in Ethiopia with the use of monthly retail price data. In line with these conceptions, the objective of the study was to model price volatility for selected agricultural commodities in Ethiopia.

\section{Data and Methodology}

\subsection{Data source}

Secondary data on the monthly price of agricultural commodities, specifically, average monthly retail prices data of teff and red pepper were obtained from Central Statistics Agency (CSA) over the period from $2010 / 11$ to $2020 / 21$. The reasons for selecting teff and red pepper are twofold: the first one is the availability of data, and the second reason is the relative importance of the two commodities in the daily consumption of the country and their increasing demand worldwide. That is, teff is one of the most important commodities for farm income and food security in Ethiopia which accounts for the largest share of the cultivated area and the total value of cereal productions [15]; CSA, (2019), it is also supposed to be the next super-grain and Injera could be the next super-food in the globe [16]. Similarly, red pepper is the essential spice for Ethiopian food. Injera could not be used without wot which uses red pepper as its main ingredient.

\subsection{Empirical Methodology}

In this study, the log-return series for the price of teff and red paper were considered since it evidenced different stylized facts of a financial time series such as leptokurtic, volatility clustering and leverage effect [17]. Leptokurtic refers to the inclination for a series to get back to have disseminations that display fat tails and peaked at the mean. Volatility clustering indicates that a large shock tends to be followed by a similar large stock, and a small shock tends to be followed by a similar small stock, and leverage effect signifies a negative correlation between an asset return and its changes of volatility and the leverage effect. Therefore, in financial studies, instead of the actual price values, it is common to analyze log return series, for its better statistical properties. The log return series is, therefore, written as: 


$$
Y_{i t}=\ln \left(\frac{p_{t}}{p_{t-1}}\right)
$$

Where: $\mathrm{p}_{\mathrm{t}}$ is average monthly price of a commodity at period $\mathrm{t}$

$\mathrm{P}_{\mathrm{t}-1}$ average monthly price of a commodity at period t-1

$Y_{\text {it }- \text { is }} \log$ returns series of a commodity at period $t$

To run a time series data analysis, it is compulsory to test stationarity of the data. In this study, Augmented Dickey-Fuller (ADF) unit root test was used to check the stationarity. When there is more than one adequate model, a valid criterion is needed for model selection. In this study, Akaike information criterion (AIC) and Schwarz information criteria (SIC) were applied for the model selection purpose.

$\mathrm{AIC}=-2 \ln (\mathrm{L})+2 \mathrm{k}$ and

$\mathrm{BIC}=-2 \ln (\mathrm{L})+\mathrm{k} \ln (\mathrm{T})$,

Where $\mathrm{L}$ is the maximized value of the likelihood function and $\mathrm{k}$ is the number of (free) parameters in the model (i.e., $\mathrm{k}=\mathrm{p}+\mathrm{q}+1$. The model with the minimum AIC and BIC value is taken as the best-fit model [18, 19]. Moreover, The Breusch-Godfrey [20] and Jarque-Bera test [21] tests were also applied to test for serial correlation and normality, respectively.

\subsection{Econometrics model specifications}

3.3.1 Autoregressive Conditional Heteroskedastic (ARCH) model

An ARCH model is an important tool in analyzing a time series data, predominantly in financial applications which is originally proposed by [4]. It could help to specify the conditional distribution of $\varepsilon t$ given the information available up to time $\mathrm{t}-1$. These models are especially useful when the goal of the study is to analyze and forecast volatility.

The model is specified as;

$$
\begin{gathered}
Y_{t}=\mu_{t}+\varepsilon_{t} \\
\delta^{2}=\omega+\alpha_{1} \varepsilon^{2}{ }_{t-1}+\alpha_{2} \varepsilon^{2}{ }_{t-2}+\alpha_{3} \varepsilon^{2}{ }_{t-3}+\cdots \\
+\alpha_{1 q} \varepsilon^{2}{ }_{t-q}
\end{gathered}
$$

Where: $\varepsilon_{t}$ is the shock at time $\mathrm{t}$

$\boldsymbol{\delta}^{2}$ is volatility at time $t$ and

$\varepsilon_{t-1}^{2}$ Is squared innovation at time t-1

\subsubsection{Generalized Autoregressive Conditional Heteroskedastic (GARCH) Model}

The generalized ARCH model was developed by [6]. A Generalized Autoregressive Conditional heteroskedasticity process is said to be a GARCH (p, q) process, and the model is variance and covariance stationary where it imposes non negativity constraint for $\alpha, \beta$ and $\omega$

The model is being expressed as a linear function of past squared innovations and its past values

The basic GARCH $(1,1)$ is expressed as;

$$
\delta^{2}=\alpha_{1} \varepsilon_{t-1}^{2}+\delta \delta_{t-1}^{2}
$$

\subsubsection{Exponential Generalized Autoregressive} Conditional Heteroskedastic (EGARCH) Model

EGARCH is another volatility model proposed by [7]. This model is expresses as follows:

$$
\operatorname{Ln} \delta^{2}=\omega+\beta \operatorname{Ln} \delta_{t-1}^{2}+\alpha_{1} \frac{\left|\varepsilon_{t-1}^{2}\right|}{\delta_{t-1}^{2}}+\gamma \frac{\varepsilon_{t-1}^{2}}{\delta_{t-1}^{2}}
$$

Where; $\alpha$ represents the symmetric effect of the model, $\quad \beta_{1}$ measures the persistence in conditional volatility shock. Large value of $\beta_{1}$ implies that volatility will take a long time to die out following a crisis in the market. The volatility shock is asymmetric when $\gamma \neq 0$, If $\gamma \neq 0$ then the model is symmetric (positive and negative shocks of the same magnitude have the same effect on volatility). When $\gamma<0$, it implies leverage effect exists and negative shocks ("bad" news) generate more volatility than positive shocks ("good" news) of the same magnitude and when $\gamma>0$, it implies that positive shocks generate more volatility than negative shocks of the same modulus.

\subsubsection{Threshold Generalized Autoregressive Conditional Heteroskedastic (TGARGH)}

The Threshold GARCH (TGARCH) model was proposed by [8] by which the model allows for asymmetric shocks to volatility that allows positive and negative shocks of equal size to have different impacts on volatility.

Simple Threshold GARCH specified as:

$$
\delta^{2}=\omega+\alpha_{1} \varepsilon_{t-1}^{2}+\beta \varepsilon_{t-1}^{2}+\gamma \varepsilon_{t-1}^{2} d_{t-1}
$$

Where dt $=1$ if is negative and 0 otherwise. In the TGARCH $(1,1)$ model, volatility tends to decreases with good news.

\subsubsection{Diagnostic Checks}

Necessary model diagnostic checking were carried out. The Breusch-Godfrey serial correlation LM test was employed in order to check for possible ARCH effects on the residuals, Correlogram of standardized residual squared for serial correlation on the residuals and Jarque - Bera for normality tests for normality on the residuals.

\section{Results and Discussions}

\subsection{Descriptive Statistics}

The study models the volatility of returns for selected agricultural commodity prices in Ethiopia using the generalized autoregressive conditional heteroskedasticity (GARCH) approach. Average monthly retail prices data of teff and red pepper from the year 2010/11 up to 2020/21 were taken and analyzed as follows: 
For better understanding of the nature and distributional properties of the price return series, summary statistics such as monthly mean returns, maximum and minimum returns, standard deviations, skewness, kurtosis, and Jarque-Bera statistics for the commodity prices return were computed and presented as follows in Table 1.

Table 1: Summary statistics for teff price return and Red paper price return series

\begin{tabular}{lcc} 
& teff Price return & red pepper price Return \\
\hline Mean & 0.64 & 0.75 \\
Standard Dev. & 4.79 & 32.64 \\
Minimum & -26.57 & -200 \\
Maximum & 28.017 & 204.296 \\
Skewness & 0.30 & 32.64 \\
Kurtosis & 21.383 & 31.127 \\
\hline
\end{tabular}

\section{Source: Author's own}

As it is shown in Table 1, the summary statistics indicates that the average monthly price returns of teff and red pepper are $0.648 \%$ and $0.757 \%$, respectively, with a monthly standard deviation of 4.79 for teff and 32.64 for red pepper. The result reviled high levels of dispersions from the average returns in the market during the study periods. The null hypotheses of zero skewness and kurtosis coefficient of 3 are rejected at $1 \%$ (0.01) significance level. High kurtosis value of $21.38342471 \%$ for teff and 31.127 for red pepper inferring that big shocks of either signs are more likely to be presented in the series which specifies the returns series are clearly leptokurtic. Similarly, skewness coefficients of 0.305050352 and 32.64029 for teff red pepper, respectively, suggesting that the monthly price returns series for both of the commodities do not follow a normal distribution. The Jarque-Bera test also confirmed $t$ rejection of normality in series since the associated $p$-value is far below $1 \%$ significance level.

\section{Figure 1: Monthly Prices of teff and red pepper}

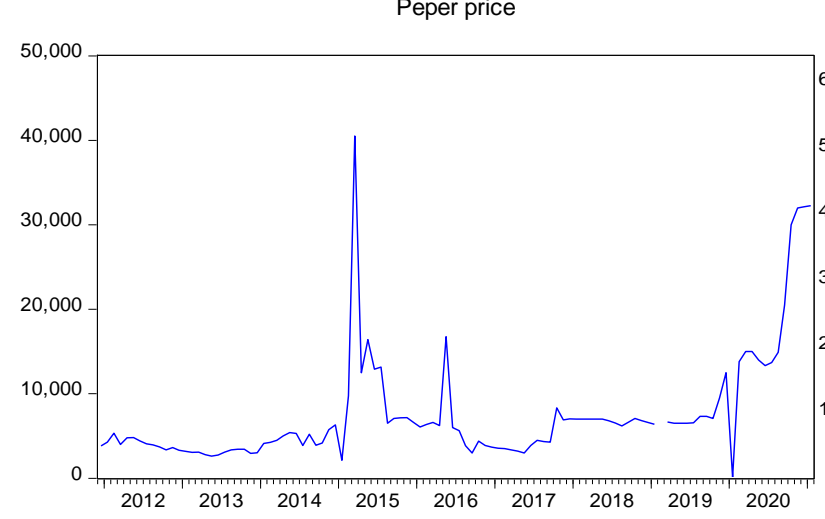

\section{Source: Author's own}

The time plot of monthly teff and red pepper price trend in the plot is not smooth as observed in the figure. This indicates that mean and variance of the commodities are heteroskedastic and the series seems to be non-stationary. Transforming the monthly price
Graphical properties of the price and return series, which is the first step in analyzing time series data, are plotted against time as follows. This could help to understand the trend as well as patterns of the original series.

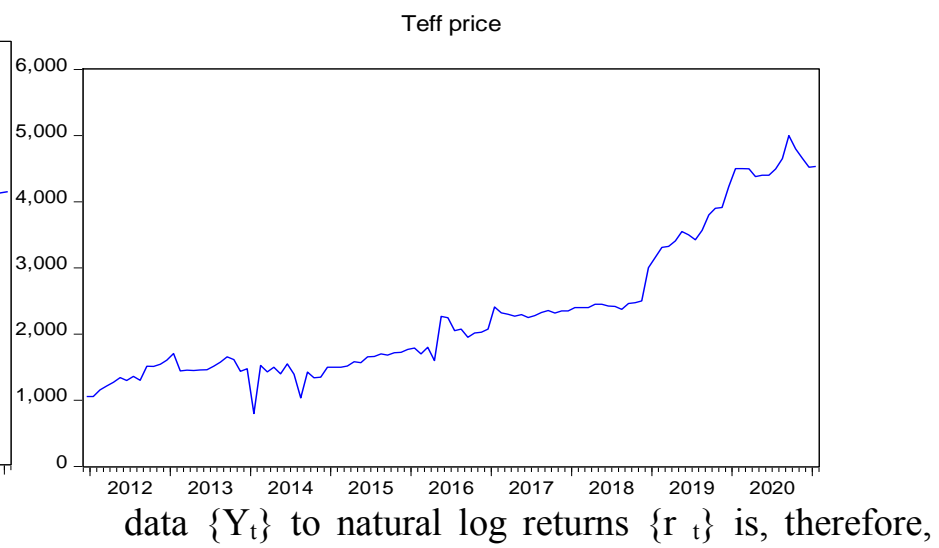
made.

In addition, the plots of the commodities price returns as function of time are shown in the following figure. The time plot of price returns indicates that some periods are more risky than others. There is also some degree of autocorrelation in the riskiness of the log returns. The amplitudes of the price returns vary over time as large changes in returns tend to be followed 
by large changes and small changes are followed by small changes.

Figure 2: Monthly return series of teff and red pepper over the study periods

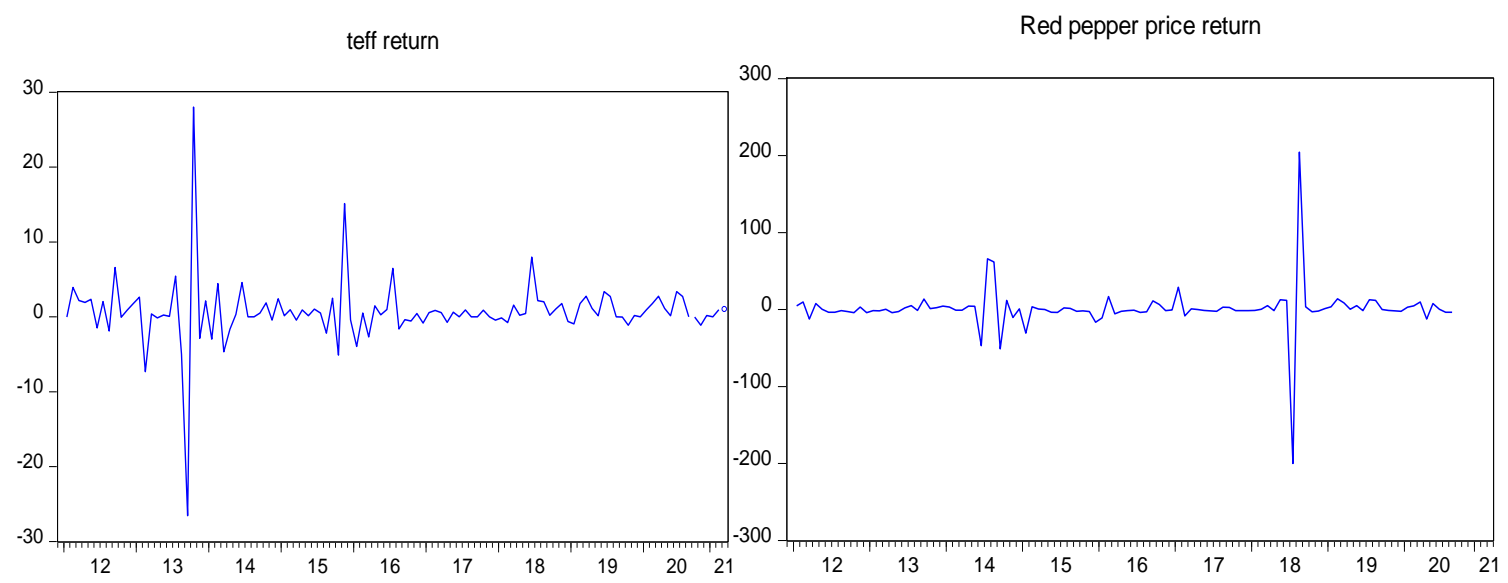

Source: Author's own

This is one of the stylized facts in the financial time series the so called volatility clustering. The volatility clustering in the series indicates that the returns are being driven by market forces. In order to meet the objective, GARCH family models were applied EViews 10 statistical package used to compute the estimates of the GARCH, volatility model parameters. Monthly price series for each selected commodity used to compute the logarithmic return series asYt $=\ln (\mathrm{pt} / \mathrm{pt}-1)$.

ADF test

\begin{tabular}{lllr}
\hline Price return series & test equation & ADFTest Statistics & P Value \\
teff & With intercept & -7.759353 & 0.0000 \\
& With trend and Intercept & -7.722723 & 0.0000 \\
red pepper & With intercept & -11.08461 & 0.0000 \\
& With trend and intercept & -11.05381 & 0.0000 \\
\hline
\end{tabular}

\section{Source: Author's own}

\subsection{Test of ARCH effect}

Test of ARCH effect is one of the most important issue to be checked before applying GARCH models.

Table 3: Hetroskedasticity test: ARCH

\section{Price return series}

$$
\text { teff }
$$

red pepper
LM Statistics

4.288312

(0.0406)

1.625696

$(0.2048)$

\subsection{Unit Root Test for Non-stationary Series}

For a time series data, one should check for stationarity in order to find an appropriate model. Therefore, in this study, Augmented Dickey-Fuller (ADF) unit root test was used to check the stationarity of the monthly natural log return series. The result is presented in Table 2. As it is observed from the table, the null hypothesis of unit root would be rejected; that is, the series are stationary at level.

Table 2. Unit Root Tests for the Series (at level)

LM test for the squared residuals of the fitted model proposed by Engle (1982) was conducted for testing heteroscedasticity.

Chi square Statistics

4.206049
$(0.0403)$
1.630869
$(0.2016)$

\section{Source: Author's own}

Although the null hypothesis states that there is no remaining $\mathrm{ARCH}$ effect, the finding indicates the existence of ARCH effect in both commodities; in fact, the null hypothesis is rejected. Therefore, it is better to estimate the ARCH model for better result since it shows the variance of return series for each commodity is time varying.

\subsection{GARCH component Model Specification}

After confirming the presence of $\mathrm{ARCH}$ effect in the residuals of the mean model, one needs to estimate GARCH model to test for the presence of asymmetry and time varying unconditional variance in the series. Various symmetric (GARCH) and asymmetric (EGARCH, TGARCH) models were considered. Then, for the model selection procedure, different symmetric and asymmetric GARCH models of 
different orders of $\mathrm{p}$ and $\mathrm{q}$. were fitted for each series. Accordingly, for symmetric GARCH model and for asymmetric EGARCH and TGARCH models under Table 4: Model selection

\begin{tabular}{|l|l|l|l|l|}
\hline Crop & Model & AIC & SIC & Lglikelihood \\
\hline \multirow{4}{*}{ teff } & ARCH & -2.69485 & -2.64814 & 162.3434 \\
\cline { 2 - 5 } & GARCH 1,1 & -2.83491 & -2.76484 & 171.6768 \\
\cline { 2 - 5 } & TGARCH & -2.82369 & -2.73027 & 172.0094 \\
\cline { 2 - 5 } & EGARCH & -2.85321 & -2.75979 & 173.7658 \\
\hline \multirow{4}{*}{ red pepper } & ARCH & -0.74526 & -0.69855 & \\
\cline { 2 - 6 } & GARCH & -0.78114 & -0.71108 & 49.47767 \\
\cline { 2 - 5 } & TGARCH & -0.97843 & -0.88501 & 62.21645 \\
\cline { 2 - 5 } & EGARCH & -1.03766 & -0.94425 & 65.74089 \\
\hline
\end{tabular}

\section{Source: Author's own}

Based on the Akika information criteria (AIC) and Schwarz criterion (SIC), EGARCH model with normal distributional assumption performs better in describing volatility of teff price return and red pepper price returns in Ethiopia under the years reviewed. The coefficients of the asymmetric terms are negative 0.039079 and positive 0.349798 for teff price return and red pepper price return, respectively, and both are statistically significant at $1 \%(0.01)$ level.

The estimate of time varying volatility is given as follows:

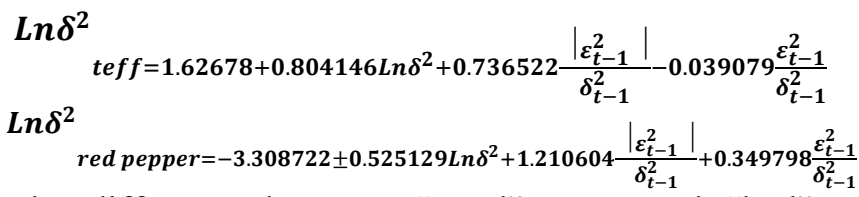

The difference between "good" news and "bad" news, which is the coefficient of asymmetry term, is 0.039079 for teff price return and 0.34978 for pepper price return. It is inferring to that there are asymmetries in the news, in which the bad news has larger effect on the volatility than the good news for both teff and red pepper price returns. In finance theory, the relationship between risk and returns

Table 5: Heteroskedasticity Test: ARCH

\begin{tabular}{lcll}
\hline F statistics & 0.006897 & Prob. F $(1,107)$ & 0.9340 \\
Obs*R-squared & 0.007025 & Prob. Chi-Square (1) & 0.9332 \\
\hline
\end{tabular}

\section{Source: Author's own}

From the results presented in Table 5, one can observe that the standardized residuals of the fitted model did not exhibit any additional ARCH effect for both series as both the F statistics and observed $\mathrm{R}$ squared are not significant.

\section{Test for serial correlation}

The null hypothesis states that there is no serial correlation in the residuals. It is implied that the statistical result of both the autocorrelation function normal assumption for residuals were selected as possible models for the price volatility. Table 4 displays the summary results. plays a pivotal role in asset pricing. If the risk is conditional and not constant over time, then the conditional expectation of the market returns is not only linear function of the conditional variance but also the information asymmetries too. Like financial time series, the leverage effect is exhibited in the return series of teff and red pepper prices. The result is consistent with findings of [11] and [23] who asserts EGARCH $(1,1)$ were appropriate in describing the symmetric and asymmetric behaviors of the $\log$ returns of agricultural commodities in Nigeria, Indonesia's coffee, respectively. In conclusion, the modeling of information, news or event is very significant determinant of this commodity's volatility.

\subsection{Checking the Adequacy of the Fitted Models}

So far it has been mentioned that EGARCH was the best model for the series, diagnostic checking for this model employed to check the ARCH effect, serial correlation and normality. Breusch-Godfrey serial correlation LM test was employed in order to check for possible ARCH effects on the residuals, Corrologram of standardized residual squared and Jarque - Bera for normality tests. Results are presented as follows:
(ACF) and partial autocorrelation function (PACF) lies within the confidence interval, and all the $\mathrm{p}$ value are more than $5 \%(0.05)$ or are not significant. It indicates that there is no serial correlation in the residuals; therefore, it fails to reject the null hypothesis

Finally even though the Jarque - Bera test statistic was significant, and hence, there was an evidence to reject the null hypothesis of normality, the selection of EGARCH $(1,1)$ model with Normal distributional assumption of residuals was well justifiable. 


\section{Conclusion}

The main objective of this study was to model price volatility for selected agricultural commodities in Ethiopia. To meet this objective, monthly price data on teff and red pepper were collected from CSA focusing on the data recorded from 2010/11 up to $2020 / 21$. The actual price data of the commodities were transformed to $\log$ return series taking into account its better statistical properties. Enabling conditions for a financial time series data were considered in the analysis; for this purpose Akaike information criterion (AIC) and Schwarz information criteria (SIC) were applied to select the appropriate model. Residuals were diagonized through BreuschGodfrey serial correlation LM test for ARCH effects on the residuals, Corrologram of standardized residual squared for serial correlation on the residuals and Jarque - Bera for normality tests for normality on the residuals.

The data analysis results showed that the price return series of teff and red pepper demonstrated the characteristics of financial time series, such as leptokurtic distributions and volatility clustering which provides an adequate ground for the use of GARCH family models. Moreover, the presence of $\mathrm{ARCH}$ effects in the residuals of the conditional mean equation is supported by the ARCH-LM tests. In this study, both symmetric GARCH $(1,1)$, GARCH $(2,0)$ and asymmetric (EGARCH) and TGARCH models were considered in order to model the price return volatility of teff and red pepper in the Ethiopian market.

Accordingly, based on the Akaika information Criteria and AIC and/or Schwarz information criteria (SIC), asymmetric EGARCH model with Normal distributional assumption of residuals was found to be a better fit for the price return volatility of teff and red pepper. This implies that there is asymmetry in the news, in which the "bad" news has larger effect on the volatility than the "good" news for both teff and red pepper price returns. In conclusion, as EGARCH is the better fit model for the teff and red pepper price returns, modelling of information, news or event are very significant determinant of assets volatility.

In general, the findings of this study demonstrates that, volatility exist in the series, and EGARCH was the best fit model in modelling price return volatility of teff and red pepper, which suggests that market participants, whether they be farmers or investors, can get prepared for shifts in market momentum and in dealing with market choices.

Suggestion for further study: The finding of this study shows green light for the application of volatility modelling using a GARCH approach. This study mainly focused on two crops i.e one teff from cereal and the other red pepper from spices. Therefore, In the future research more crops from cereals, root crops, oilseeds and pulses be tested and future forecasting need to be done.

\section{References:}

[1] Shiferaw, Y. A. (2012). Modeling Volatility of Price of Some Selected Agricultural Products in Ethiopia: ARIMA-GARCH Applications. SSRN Electronic Journal, 113. https://doi.org/10.2139/ssrn.2125712

[2] Markowitz, H. (1952) Portfolio Selection. The Journal of Finance, Vol. 7, No. 1, pp. 7791. March. 1952. www.jstor.org.proxy.lib.chalmers.se/stable/ $10.2307 / 2975974$ ? origin=api $(2012-1030)$

[3] Mandelbrot, B. (1963). New methods in statistical economics. Journal of political economy, 71(5), 421-440.Engle (1982)

[4] Engle, R. F. (1982). Autoregressive Conditional Heteroscedasticity with Estimates of the Variance of United Kingdom Inflation. Econometrica, 50(4), 987. https://doi.org/10.2307/1912773

[5] Abebe, T. H., Woldesenbet, E. G., \& Zeleke, B. L. (2020). Statistical Analysis of Price Volatility of Agricultural Commodities Traded at the Ethiopian Commodity Exchange (ECX) Using Multiplicative GARCH-MIDAS Two-component Model. Global Business Review, 0972150919895628.

[6] Bollerslev, T. (1986). Generalized autoregressive conditional heteroskedasticity. Journal of Econometrics, 31(3), 307-327. https://doi.org/10.1016/03044076(86)90063-1

[7] Nelson, D. B. (1991). Conditional heteroskedasticity in asset returns: A new approach. Econometrica: Journal of the Econometric Society, 347-370

[8] Zakoian, J.M., (1994), Threshold Heteroskedastic Models, Journal of Economic Dynamics and Control, 18(5), pp. 931-955.

[9] Thiyagarajan, S., Naresh, G., \& Mahalakshmi, S. (2015). Forecasting 
volatility in Indian agri-commodities market. Global Business \& Finance Review (GBFR), 20(1), 95-104.

[10] Le Roux, C. L. (2017, July). Volatility Modelling of Agricultural Commodities: Application of Selected GARCH Models. In International Conference on Applied Economics (pp. 343356). Springer, Cham.

[11] Adugh, K. D. (2019). Modeling Volatility of Agricultural Commodity Food Price Index in Nigeria using ARMAGARCH Models Modeling Volatility of Agricultural Commodity Food Price Index in Nigeria using ARMA-GARCH Models. $3(1), 55-75$.

[12] Lama, A., Jha, G. K., Paul, R. K., \& Gurung, B. (2015). Modelling and Forecasting of Price Volatility: An Application of GARCH and EGARCH Models. Agricultural Economics Research Review, 28(1), https://doi.org/10.5958/09740279.2015.00005.

[13] Ayele, A. W., Gabreyohannes, E., \& Tesfay, Y. Y. (2017). Macroeconomic determinants of volatility for the gold price in Ethiopia: the application of GARCH and EWMA volatility models. Global Business Review, 18(2), 308-326.

[14] Muanenda \& Yohannes. (2018) Modeling and Forecasting the Volatility of the Export Price of Sesame in Ethiopia , Journal of Economics and Sustainable Development

[15] Tesfaw, Z., Zemedu, L., \& Tegegn, B. (2021). Technical efficiency of Teff producer farmers in Raya Kobo district, Amhara National Regional State, Ethiopia. Cogent Food \& Agriculture, 7(1), 1865594.

[16] Fikadu, A., Wedu, T. D., \& Derseh, E. (2019). Review on economics of teff in Ethiopia. Open Access Biostatistics \& Bioinformatics, 2, 1-8.

[17] Rachev, S. T., Kim, Y. S., Bianchi, M. L., \& Fabozzi, F. J. (2011). Financial models with Lévy processes and volatility clustering (Vol. 187). John Wiley \& Sons.

[18] Brockwell, P. J., \& Davis, R. A. (2009). Time series: theory and methods. Springer Science \& Business Media.

[19] Burnham, K. P., \& Anderson, D. R. (2002). A practical information-theoretic approach. Model selection and multimodel inference, 2.

[20] Hong, Y. (1996). Consistent testing for serial correlation of unknown form. Econometrica: Journal of the Econometric Society, 837-864.

[21] Jarque, C. M., \& Bera, A. K. (1987). A test for normality of observations and regression residuals. International Statistical Review/Revue Internationale de Statistique, 163-172.

[22] Musunuru, N., Yu, M., \& Larson, A. (2013). Forecasting volatility of returns for corn using GARCH Models. Texas Journal of Agriculture and Natural Resources, 26, $42-55$.

[23] Rahayu (2015) Volatility Analysis andVolatility Spillover Analysis of Indonesia's Coffee Price Using Arch/Garch, and Egarch Model Journal of Agricultural Studies

\section{Creative Commons Attribution License 4.0 (Attribution 4.0 International, CC BY 4.0)}

This article is published under the terms of the Creative Commons Attribution License 4.0 https://creativecommons.org/licenses/by/4.0/deed.en_US 